\title{
Surgical Treatment of Rosai-Dorfman Intracranial Disease: Case Report and Literature Review
}

\section{Tratamento cirúrgico da doença de Rosai-Dorfman intracraniana: relato de caso e revisão da literatura}

\author{
Klisman Drescher Hilleshein ${ }^{1}$ Vinícius Galisteo Santin ${ }^{1}$ Fabrício Molon da Silva ${ }^{2}$ \\ ${ }^{1}$ Medical Student, Universidade do Oeste de Santa Catarina, Joaçaba, \\ SC, Brazil \\ 2 Neurosurgeon, Hospital Universitário Santa Terezinha, Joaçaba, SC, \\ Brazil

\begin{abstract}
Address for correspondence Klisman Drescher Hilleshein, MD, Curso de Medicina da Universidade do Oeste de Santa Catarina, Rua Frederico Mayer, s/n, Centro, Quilombo, SC, Brazil 89850-000
\end{abstract} \\ (e-mail: klismandrescherhilleshein@gmail.com).
}

Arq Bras Neurocir 2018;37:239-241.
Abstract
Keywords
- Rosai-Dorfmann disease
- seizures
- neurosurgery
- meningioma

\section{Resumo \\ Palavras-Chave \\ - doença de Rosai- Dorfman \\ - convulsões \\ - neurocirurgia \\ - meningioma}

Rosai-Dorfman disease is a benign lymphoproliferative disease with rare occurrence in the overall population. The characteristic findings of the disease are emperipolesis on microscopy and S-100 protein positivity on immunohistochemistry. The present report describes the case of a 57-year-old man who presented with repeated seizures, urinary retention, and ataxia. Satisfactory results were obtained with surgical treatment. The diagnosis was confirmed by immunohistochemistry.

\begin{abstract}
A doença de Rosai-Dorfman é uma doença linfoproliferativa de caráter benigno com ocorrência rara na população global. Os achados característicos da doença são emperipolese no exame de microscopia e positividade para proteína S-100 no exame imuno-histoquímico. O presente estudo descreve o caso de um homem de 57 anos que apresentava convulsão de repetição, retenção urinária e ataxia. Foi obtido resultado satisfatório com o tratamento cirúrgico. O diagnóstico foi confirmado por imunohistoquímica.
\end{abstract}

\section{Introduction}

In 1969, Rosai-Dorfman disease was first reported as a sinus histiocytosis with massive lymphadenopathy in a young black man. ${ }^{1}$ The disease presented with bilateral, painless and massive cervical lymphadenopathy associated with malaise, fever, normocytic anemia, hemolytic anemia, neutrophilic, high erythrocyte sedimentation rates, and polyclonal gammopathy. ${ }^{2}$

It is estimated that the incidence of the disease is of 1 case per 2 million individuals, affecting predominantly children and young adults, with a slight predominance in males. ${ }^{3}$ Extranodal involvement is documented in $43 \%$ of the patients, occasionally accompanied by lymphadenopathy. The extranodal sites, in descending order of frequency, are the skin, the nasal cavity, the paranasal sinuses, the eyelids, the orbits, the bones, the salivary glands, and the central nervous system (CNS). The CNS can be involved in less than $5 \%$ of the cases, and in $90 \%$ of them, the leptomeninges are affected. ${ }^{4}$

\section{Case Report}

The case described in the present study is that of a male patient who was 57 years old at the time of the diagnosis. He presented with repetitive convulsive crises, urinary retention, and ataxia. received

July 4, 2015

accepted

January 7, 2016

published online

March 9, 2016
DOI https://doi.org/

10.1055/s-0036-1578569. ISSN 0103-5355.
Copyright $(2018$ by Thieme Publicações License terms Ltda, Rio de Janeiro, Brazil
()(1) $\Theta \circledast$ 


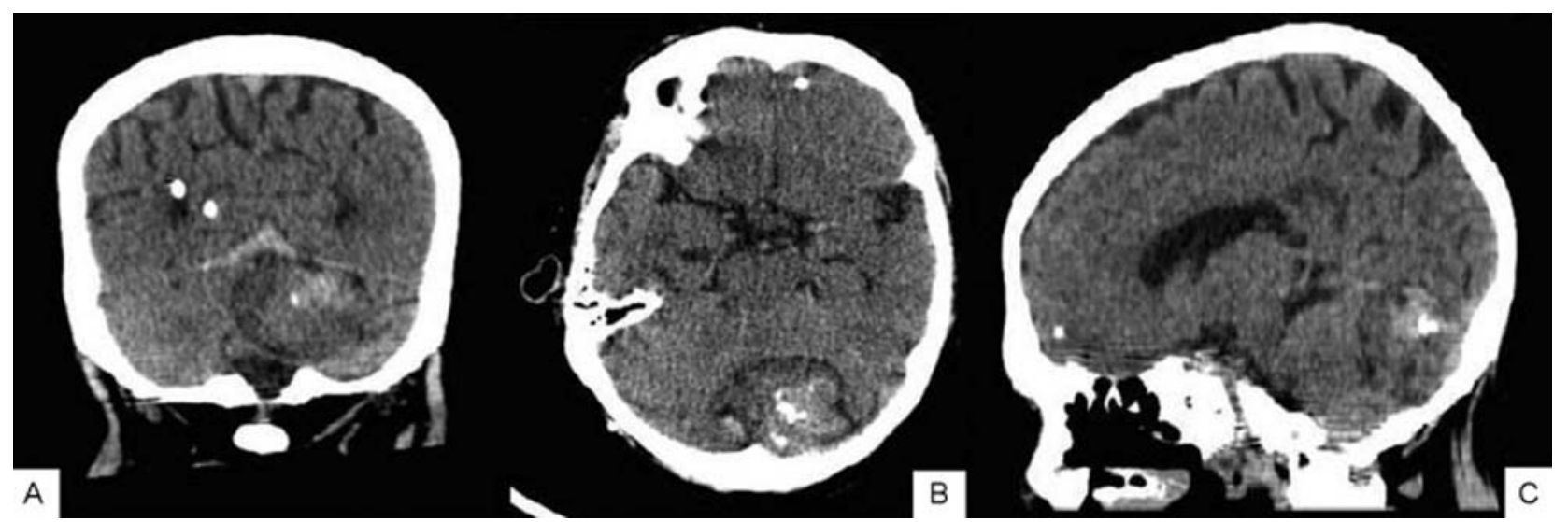

Fig. 1 Computed tomography of the skull showing a posterior fossa lesion, adjacent to the cerebellum tentorium. (A) coronal cut; (B) axial cut; (C) sagittal cut.

A computed tomography (CT) exam revealed heterogeneous expansive formations in an intraventricular situation occupying the posterior portion of the third ventricle and part of the right lateral ventricle, as well as another extra-axial lesion in the posterior fossa. - Fig. 1 demonstrates these findings.

It is suggested that the lesions found in the imaging examination may correspond to primary lesions of the meningothelial lining (meningiomas) in the tentorium, as well as signs of subfalcine herniation due to the effect of the intracranial masses.

During hospitalization, the patient presented improvement of the clinical picture with the use of corticosteroids. A ventriculoperitoneal shunt was performed to attenuate the hydrocephalus. The surgery was performed because of the alleged cerebellar tentorium meningioma. Both the surgery and the postoperative period were uneventful.

With the tumor duly resected, the patient was referred for an anatomopathological examination, which revealed two expansive brain lesions, one intraventricular in the third right lateral ventricle, and the other extra-axial in the posterior fossa. The macroscopy presented as irregular fragments of excision of a skull base lesion, of a soft and light brown appearance.

The microscopy described the tumor as fragments of brain lesions with proliferation of cells with microvacuolar cytoplasm of uncertain behavior and areas of dense connective tissue with foci of dystrophic calcification. It was recommended, for diagnostic elucidation, an immunohistochemical study.

The immunohistochemical study suggested the diagnosis of Rosai-Dorfman disease because there were fragments of hypercellular cerebral parenchyma at the expense of histiocytic cells, several of them xanthomatous in appearance, while others showed a more eosinophilic cytoplasm.

The S-100 marker was found to be positive (-Fig. 2). There was a chronic mononuclear inflammatory infiltration, drawing attention to the presence of cells with an occasional intracytoplasmic location in the histiocytes (emperipolesis).

\section{Discussion}

The age and gender of the patient in the present case is similar to the age and gender of patients from cases reported in the literature. $^{5-7}$ The clinical presentation of intracranial tumors is dependent on the location of the tumor. The patient in the present report had recurrent seizures, urinary retention, and ataxia. Other reports include headache and convulsion, ${ }^{7}$ in addition to cognitive decline, visual blurring, and hemianopsia. ${ }^{4}$

The origin of Rosai-Dorfman disease, sometimes associated with the Epstein-Barr virus, ${ }^{8}$ or with the varicella-zoster virus, remains invariant, with involution with the use of acyclovir. ${ }^{9}$ It may also be associated with other immune disorders, such as hemolytic anemia, polyarthritis, rheumatoid arthritis, glomerulonephritis, asthma, and juvenile diabetes. ${ }^{8}$ Thus, the present study aimed to describe a case of Rosai-Dorfman disease that occurred in southern Brazil.

If there is no pathognomonic signal, the radiological exams suggest an intracranial mass. In addition to meningioma, a differential diagnosis for eosinophilic granuloma, lymphoproliferative disorder, plasma cell granuloma, and infectious diseases should be considered. ${ }^{7}$ Tumors of the Rosai-Dorfman disease are homogeneous, lobulated, hyperattenuating, and without calcifications.

On the other hand, in the magnetic resonance imaging (MRI) exam, in T1 weighting, the tumors are homogeneous,

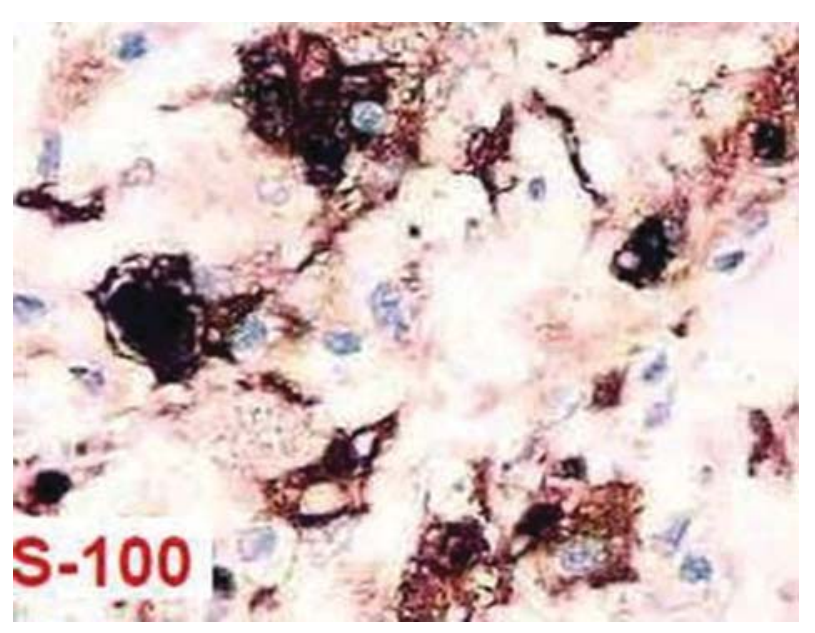

Fig. 2 Image of the immunohistochemical study demonstrating histiocytes reactive to the $\mathrm{S}-100$ protein. 
lobulated, and isointense to the cerebral parenchyma. In T2 weighting, the nodulations are heterogeneous, hypo/isointense to the parenchyma, and with intensity similar to that of the dura mater. ${ }^{4}$ They also present the dural tail sign, indicating insertion of the lesions in the dura mater. ${ }^{7}$

Given the suspicion of meningioma, surgery was chosen as a therapeutic option. ${ }^{10}$ Surgery, whether followed by corticosteroids or not, is the best therapeutic option for tumors of the Rosai-Dorfman disease. ${ }^{4}$

The macroscopic description in the literature is of a yellowish mass of elastic consistency, ${ }^{4}$ or white-gray, ${ }^{7}$ differing from the present case. In microscopy, the phenomenon described as emperipolesis consists of histiocytes with large vesicular nuclei having pale eosinophilic cytoplasm containing lymphocytes or erythrocytes within them. ${ }^{4}$ Immunoreactivity to S100 protein is very suggestive of Rosai-Dorfman disease. ${ }^{4,6,7}$ The immunoreactivity for CD1a markers, which are markers for Langerhans histiocytosis, should be negative. ${ }^{6}$

Because the tumor is benign, surgery with partial or total excision has a satisfactory outcome. ${ }^{7}$ The surgery may be followed by corticosteroid therapy, antineoplastic chemotherapy, and radiotherapy. ${ }^{4}$ Unfavorable results have been reported in cases of extranodal multisystemic disease, of immunological abnormalities, or in cases in which there is involvement of the kidney, of the liver, and of the lower respiratory tract. ${ }^{8}$ Rosai-Dorfman disease may have a lethal outcome despite intensive treatment with external beam radiation, interferon, cyclosporine, methylprednisolone, etoposide (VP16), and vinblastine. ${ }^{2}$

\section{Conclusion}

The literature demonstrates a benign essence for Rosai-Dorfman disease, however, with an obscure etiology, which can affect all age groups and have heterogeneous clinical manifestations.
Even though it is the main differential diagnosis of meningiomas, through radiology it is impossible to make the final diagnosis,. The pathological anatomy is fundamental for diagnostic confirmation. The microscopy showed characteristic emperipolesis findings, and the immunohistochemistry showed immunoreactivity for S-100 protein, with no reactivity for CD1a.

Thus, surgery provides good survival outcomes and has been adopted as the therapeutic method of choice.

\section{References}

1 Rosai J, Dorfman RF. Sinus histiocytosis with massive lymphadenopathy. A newly recognized benign clinicopathological entity. Arch Pathol 1969;87(01):63-70

2 Warrier R, Chauhan A, Jewan Y, Bansal S, Craver R. Rosai-Dorfman disease with central nervous system involvement. Clin Adv Hematol Oncol 2012;10(03):196-198

3 Mahzoni P, Zavareh MHT, Bagheri M, Hani N, Moqtader B. Intracranial ROSAI-DORFMAN Disease. J Res Med Sci 2012;17(03):304-307

4 Adeleye AO, Amir G, Fraifeld S, Shoshan Y, Umansky F, Spektor S. Diagnosis and management of Rosai-Dorfman disease involving the central nervous system. Neurol Res 2010;32(06):572-578

5 Sameshima T, Morita A, Tanikawa R, Tsuboi T, Kitai R. Isolated Intracranial Rosai-Dorfman Disease Mimicking Convexity Meningioma: A Case Report. J Clin Exp Pathol 2012;2(05):2-5

6 Konishi E, Ibayashi N, Yamamoto S, Scheithauer BW. Isolated intracranial Rosai-Dorfman disease (sinus histiocytosis with massive lymphadenopathy). AJNR Am J Neuroradiol 2003;24(03):515-518

7 Chen S-C, Teo B-T, Yen P-S. Isolated Intracranial Rosai-Dorfman Disease: Report of 2 Cases and Review of the Literature. Tzu Chi Med J. 2007;19(02):90-93

8 Cooper SL, Jenrette JM. Rosai-Dorfman disease: management of CNS and systemic involvement. Clin Adv Hematol Oncol 2012;10 (03):199-202

9 Baildam EM, Ewing CI, D’Souza SW, Stevens RF. Sinus histiocytosis with massive lymphadenopathy (Rosai-Dorfman disease): response to acyclovir. J R Soc Med 1992;85(03):179-180

10 Melo-Souza SE. Tratamento das doenças neurológicas. Rio de Janeiro: Guanabara Koogan; 2000 